\title{
Vitamin C inhibits leptin secretion and some glucose/lipid metabolic pathways in primary rat adipocytes
}

\author{
D F Garcia-Diaz, J Campion, F I Milagro, N Boque, M J Moreno-Aliaga and J A Martinez \\ Department of Nutrition and Food Sciences, Physiology and Toxicology, University of Navarra, c/lrunlarrea 1, 31008 Pamplona, Spain \\ (Correspondence should be addressed to J A Martinez; Email: jalfmtz@ unav.es)
}

\begin{abstract}
Antioxidant-based treatments are emerging as an interesting approach to possibly counteract obesity fat accumulation complications, since this is accompanied by an increased systemic oxidative stress. The aim of this study was to analyze specific metabolic effects of vitamin C (VC) on epididymal primary rat adipocytes. Cells were isolated and incubated for $72 \mathrm{~h}$ in culture medium, in the absence or presence of $1.6 \mathrm{nM}$ insulin, within a range of VC concentrations $(5-1000 \mu \mathrm{M})$. Glucose- and lipid-related variables as well as the secretion/expression patterns of several obesity-related genes were assessed. It was observed that VC dose dependently inhibited glucose uptake and lactate production, and also reduced glycerol release in both control and insulin-treated cells. Also, VC caused a dramatic concentration-dependent fall in leptin secretion especially in insulin-stimulated cells. In addition, VC $(200 \mu \mathrm{M})$ induced Cdkn1a and Casp8, partially inhibited Irs3, and together with insulin drastically reduced Gpdh (listed as Gpd1 in the MGI database) gene expressions. Finally, VC and insulin down-regulatory effects were observed on extracellular and intracellular reactive oxygen species production respectively. In summary, this experimental assay describes a specific effect of VC in isolated rat adipocytes on glucose and fat metabolism, and on the secretion/expression of important obesity-related proteins.
\end{abstract}

Journal of Molecular Endocrinology (2010) 45, 33-43

\section{Introduction}

Worldwide, obesity is emerging as one of the major health threats (Powers et al. 2007). Indeed, it is well known that an excessive body fat accumulation, which defines this disease, could lead to several associated clinical manifestations such as type 2 diabetes, metabolic syndrome features, cardiovascular events, and arthritis (Bray 2004). These effects are related to a white adipose tissue (WAT) overgrowth and also to an impaired production and secretion of endogenous products by the enlarged adipocytes or the macrophages coexisting in the tissue (Bray 2004), which often have pro-inflammatory properties (Fantuzzi 2005). Actually, it has been reported that several inflammatory products derived from this tissue, such as TNF- $\alpha$, IL6, MCP-1 (listed as CCL2 in the MGI database), and iNOS (NOS2), correlate with increased body adiposity (Ferrante 2007). In addition, it has been reported that inflammatory-related pathways are activated in obesity and insulin resistance states (Yuan et al. 2001, Cai et al. 2005). Besides the secretion of these pro-inflammatory cytokines, the adipose tissue produces other substances that also have important local and systemic effects (Fantuzzi 2005). Among these molecules, leptin, which is related to the control of food intake and energy expenditure (Zhang et al. 1994), and adiponectin, which is related to significant insulin sensitivity improvements (Kim et al. 2007), as well as visfatin, which has been reported to have controversial associations with insulin resistance and obesity, are metabolically relevant (Fukuhara et al. 2005, Haider et al. 2006, Varma et al. 2007).

On the other hand, in obesity, a mitochondrial dysfunction and reactive oxygen species (ROS) overproduction as well as an association between oxidative stress and insulin resistance have been observed (Martinez 2006). In this sense, in obese patients (Vincent \& Taylor 2006) and in overweight animal models (Furukawa et al. 2004, Milagro et al. 2006), an elevated oxidative stress has been documented. Furthermore, depletion of the antioxidant defenses has also been described in obesity (Mutlu-Turkoglu et al. 2003). This oxidative stress unbalanced status is related to chronic inflammation and hyperleptinemia (Vincent \& Taylor 2006). Thus, induced monocyte migration to the adipose tissue and high secretion levels of some WAT-secreted adipokines are directly implicated in the obesity-associated ROS overproduction. This fact links the pathogenic secretion pattern of WAT with an enhanced oxidative stress status (Moreno-Aliaga et al. 2005).

The abilities of antioxidant vitamins include free radical depletion, nitric oxide synthesis or release control, ROS production inhibition, and the induction of antioxidant enzymes (Flora 2007). In this context, it 
has been observed that the dietary antioxidant ascorbic acid or vitamin $\mathrm{C}(\mathrm{VC})$ is negatively associated with the presence of several conditions such as hypertension, gallbladder disease, stroke, cancers, and atherosclerosis (Bsoul \& Terezhalmy 2004), and also with the occurrence of obesity (Canoy et al. 2005, Johnston 2005). Among the beneficial effects of ascorbic acid on obesity-related mechanism, the modulation of adipocyte lipolysis (Misekova et al. 1993, Hasegawa et al. 2002, Senen et al. 2002, Garcia-Diaz et al. 2009), glucocorticoid release from adrenal glands (Doulas et al. 1987), hyperglycemia improvement and glycosylation decrease in obese diabetic mice (Abdel-Wahab et al. 2002), and an inhibition of the inflammatory response (Carcamo et al. 2002) have been described.

Taking all these findings into account, in this study, an attempt to identify the potential relationships between gene expression and secretion of WAT adipokines as affected by VC treatment in rat primary culture adipocytes was made. Moreover, this work aimed to analyze whether this antioxidant treatment has implications concerning the glucose and lipid metabolism and in the oxidative stress status of rat fat cells.

\section{Materials and methods}

\section{Materials}

DMEM, $100 \times$ minimal essential medium $($ MEM) non-essential amino acids, penicillin/streptomycin, heat-inactivated fetal bovine serum (FBS), $10 \times$ MEM, nystatin, Trizol Reagent, and M-MLV reverse transcriptase were obtained from Invitrogen. BSA, HEPES, insulin, and $2^{\prime}, 7^{\prime}$-dichlorofluorescein $(\mathrm{DCFH})$ were all obtained from Sigma-Aldrich Company. Collagen (Purecol) was purchased from Nutacon (Leimuiden, The Netherlands). Type I collagenase was supplied by Worthington Biochemical Corporation (Lakewood, NJ, USA), and VC by Panreac Quimica (Barcelona, Spain). Glycerol-3-phosphate dehydrogenase (GPDH, listed as GPD1 in the MGI database), glycerol kinase (GK, GYK), ATP, and NAD were obtained from Roche Diagnostics.

\section{Animals}

Eight-week-old male Wistar rats $( \pm 250 \mathrm{~g}$ weight $)$ that were supplied by the Center for Applied Pharmacobiology Research (CIFA, Pamplona, Spain) were housed in temperature-controlled rooms at $21-23{ }^{\circ} \mathrm{C}$ under a $12-\mathrm{h}$ light cycle (lights were switched off at $2000 \mathrm{~h}$ ). The rats $(n=7)$ were killed, and their epididymal WAT was removed for adipocyte isolation. All the procedures were performed according to the European National and Institutional Guidelines of the Animal Care and Use Committee at the University of Navarra.

\section{Adipocyte isolation and culture}

Primary cultures were performed according to protocols described elsewhere (Lorente-Cebrian et al. 2009). Epididymal WAT (3-4 g) of each rat $(n=7)$ was minced using scissors in HEPES-phosphate buffer $(\mathrm{pH} 7 \cdot 4$; containing $5 \mathrm{mM}$ D-glucose, $2 \% \mathrm{BSA}, 135 \mathrm{mM} \mathrm{NaCl}$,

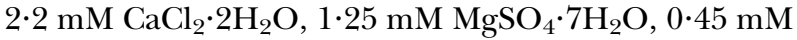
$\mathrm{KH}_{2} \mathrm{PO}_{4}, 2 \cdot 17 \mathrm{mM} \mathrm{Na} \mathrm{HPO}_{4}$, and $10 \mathrm{mM}$ HEPES). WAT fragments were digested in the same buffer with type I collagenase $(1.25 \mathrm{mg} / \mathrm{ml}$ per $0.5 \mathrm{~g}$ tissue $)$ at $37^{\circ} \mathrm{C}$ with gentle shaking for $30 \mathrm{~min}$. The resulting cell suspension was diluted in the buffer, and then the adipocytes were isolated from the undigested tissue by filtration through a $400-\mu \mathrm{m}$ nylon mesh and washed three times with alternate centrifugations at $500 \mathrm{~g}$. for $6 \mathrm{~min}$. Isolated adipocytes were then resuspended in DMEM supplemented with $1 \%$ FBS, $100 \mathrm{U} / \mathrm{ml}$ penicillin and $100 \mu \mathrm{g} / \mathrm{ml}$ streptomycin, $100 \mathrm{U} / \mathrm{ml}$ nystatin, and $1 \times$ MEM non-essential amino acids, followed by incubation for $40 \mathrm{~min}$ at $37^{\circ} \mathrm{C}$ in $5 \% \quad \mathrm{CO}_{2}$. The resulting isolated adipocytes $(150 \mu \mathrm{l}$ of a 2:1 mix of packed cells/culture medium) were then plated on $500 \mu \mathrm{l}$ of a collagen matrix ( $\mathrm{pH} 7,7$ parts collagen: 1 part $10 \times$ MEM) in six-well culture plates. After $40-50 \mathrm{~min}$ of incubation at $37^{\circ} \mathrm{C}$ in $5 \% \quad \mathrm{CO}_{2}$, the culture medium containing 0 or $1.6 \mathrm{nM}$ insulin and different concentrations $(0,5,10,50,200$, and $1000 \mu \mathrm{M})$ of VC was added. Cells were maintained in an incubator at $37^{\circ} \mathrm{C}$ in $5 \% \mathrm{CO}_{2}$ up to $72 \mathrm{~h}$. VC was freshly added every day. Aliquots of the culture medium were collected at the end of the experimental trial, and conserved at $-80^{\circ} \mathrm{C}$ for further assays.

\section{Culture medium determinations}

All the assays were performed on 72-h treatment samples. Cell viability $(n=5)$ was measured using the lactate dehydrogenase (LDH) Cytotoxicity Assay Kit according to the manufacturer's indications (Cayman Chemical Company, Ann Arbor, MI, USA). LDH activity $(\mu \mathrm{U} / \mathrm{ml})$ in the culture medium was used as an indicator of cell membrane integrity, and thus as a measurement of cell necrosis/apoptosis. Cell viability was assayed at the end of the experimental period in control and insulin/VC $(200 \mu \mathrm{M})$-treated cells. Glucose and lactate concentrations in the medium were measured using the HK-CP kit obtained from ABX Diagnostic (Montpellier, France) and the L-lactate kit obtained from Randox Laboratories (Crumlin, UK) respectively using an automatized COBAS MIRA equipment (Roche). The amount of released carbon as lactate per amount of carbon taken up as glucose over this time (glucose to lactate \%) was calculated as (lactate concentration/glucose concentration) $\times 100$. Glycerol concentration in the medium, as a measure 
of the adipocyte lipolytic response, was determined by a colorimetric method (Campion \& Martinez 2004). Briefly, culture medium of each sample was incubated with $25 \mu \mathrm{g} / \mathrm{ml} \mathrm{GPDH}$ and $250 \mathrm{mU} / \mathrm{ml} \mathrm{GK}$ in the presence of $43.6 \mathrm{mM} \mathrm{MgCl}_{2}, 200 \mathrm{mM}$ glycine, $5.2 \%$ hydrazine, $1.24 \mathrm{mM}$ ATP, and $573 \mu \mathrm{M}$ NAD for $40 \mathrm{~min}$. Finally, sample absorbance was measured at $340 \mathrm{~nm}$. Leptin secretion was determined using the Rat Leptin ELISA kit obtained from Linco Research (St Charles, MO, USA), adiponectin using the Mouse/Rat Adiponectin ELISA kit obtained from B-Bridge International (Mountain View, CA, USA), and visfatin using the Visfatin EIA kit obtained from ALPCO Diagnostics (Salem, NH, USA).

\section{Gene expression assays}

Total RNA was isolated from isolated epididymal adipocytes incubated with or without $1.6 \mathrm{nM}$ insulin and treated or not treated with $200 \mu \mathrm{M}$ VC using Trizol (Invitrogen) according to the manufacturer's protocol. Purified total RNA from adipocytes was then treated with DNAse (DNAfree kit; Ambion Inc., Austin, TX, USA), and used to generate cDNA with M-MLV reverse transcriptase (Invitrogen). Relative real-time PCR was performed on an ABI PRISM 7000 HT Sequence Detection System (Applied Biosystems, Foster City, CA, USA). Taqman probes for rat leptin, adiponectin, visfatin, $G p d h$, insulin receptor substrate 3 (Irs3), cyclin-dependent kinase inhibitor 1A (Cdkn1a), caspase 8 (Casp 8$), G a p d h$, and $18 S$ rRNA were also supplied by Applied Biosystems. All the expression levels of the target genes studied were normalized by the two selected internal controls, Gapdh and 18S, applying the GeNorm software (http://medgen.ugent.be/ jvdesomp/genorm/; Vandesompele et al. 2002).

\section{ROS determination}

DCFH was used for intracellular and extracellular ROS concentration measurements with a protocol described elsewhere (Fu et al. 2008). Once inside the cell, this molecule is cleaved by endogenous esterases and can no longer pass out of the cell membrane. The de-esterified product becomes a fluorescent compound after oxidation by ROS (Brandt \& Keston 1965). Briefly, cells were incubated with $10 \mu \mathrm{M}$ DCFH for $40 \mathrm{~min}$ at $37^{\circ} \mathrm{C}$ in $5 \% \mathrm{CO}_{2}$, frozen for at least $1 \mathrm{~h}$ at $-80^{\circ} \mathrm{C}$, and then lysed using $1000 \mu \mathrm{l}$ lysis buffer $(150 \mathrm{mM} \mathrm{NaCl}$, $0 \cdot 1 \%$ Triton, and $10 \mathrm{mM}$ Tris). Finally, $200 \mu \mathrm{l}$ of each lysate were plated on a 96-well black plate (Labsystems, Barcelona, Spain). For extracellular ROS determinations, $300 \mu \mathrm{l}$ of culture medium of each sample (from $1000 \mu \mathrm{l}$ of total incubation volume) after the 72-h treatment were also incubated with $10 \mu \mathrm{M}$ DCFH for
$40 \mathrm{~min}$ at $37^{\circ} \mathrm{C}$ in $5 \% \mathrm{CO}_{2}$, frozen for at least $1 \mathrm{~h}$ at $-80^{\circ} \mathrm{C}$, and then $200 \mu \mathrm{l}$ from this incubation mix were loaded on a 96-well black plate. Finally, fluorescence intensity was measured using a POLARstar spectrofluorometer plate reader (BMG Labtechnologies, Offenburg, Germany) at an excitation of $485 \mathrm{~nm}$ wavelength and at an emission of $530 \mathrm{~nm}$ wavelength.

\section{Statistical analysis}

Due to reduced sample size in some of the experimental groups, non-parametric analyses were performed. Thus, Kruskal-Wallis test was used followed by Mann-Whitney $U$ tests for further comparisons. Results are shown using box and whisker plots expressing median and interquartile range. For ROS determinations, parametric analyses (two-way ANOVA) were performed due to their normal distribution, which was determined by the Shapiro-Wilk test, and equal sample number among experimental groups. These results were expressed by mean \pm s.E.M. A probability of $P<0.05$ was set for determining significant differences. All the analyses were performed using the GraphPad Prism 4.0 software (GraphPad Software, San Diego, CA, USA) and the SPSS 15.0 for Windows software (SPSS Inc., Chicago, IL, USA).

\section{Results}

\section{Glucose and lipid metabolism}

Initially, LDH cytotoxicity assay presented no statistical differences among the experimental groups, indicating that neither insulin nor VC induced necrosis/apoptosis in rat epididymal adipocytes after the 72-h treatment at the assayed doses (data not shown). Adipocytes treated with VC exhibited lower glucose uptake than controls (Fig. 1A). On the other hand, insulin induced a marginally significant $(P=0 \cdot 053)$ inducing effect on the glucose uptake of the adipocytes. Specifically, among the adipocytes without insulin treatment, $200 \mu \mathrm{M} \mathrm{VC}$ induced a significant decrease in the glucose uptake compared with the controls $(P<0 \cdot 05)$. Moreover, in adipocytes that were incubated with insulin, the VC treatment induced a substantial and concentration-dependent decrease in the glucose uptake, with this reduction being statistically significant with concentrations over $50 \mu \mathrm{M}$ versus adipocytes treated with insulin alone $(P<0.05$ for 50 , and $P<0 \cdot 01$ for 200 and $1000 \mu \mathrm{M})$.

On the other hand, the lactate production of the adipocytes was not significantly affected by the insulin treatment (Fig. 1B), but increasing concentrations of VC induced a lower production of this anaerobic metabolite, which was statistically significant over 
A
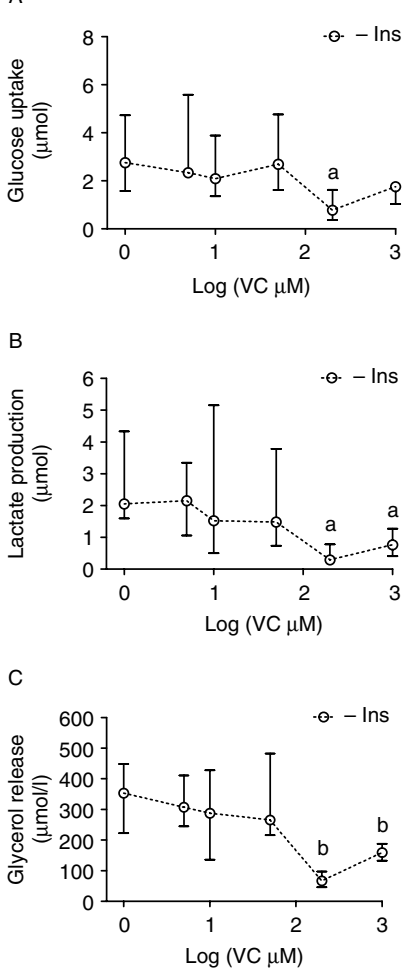

Kruskal-Wallis $P<0.001$

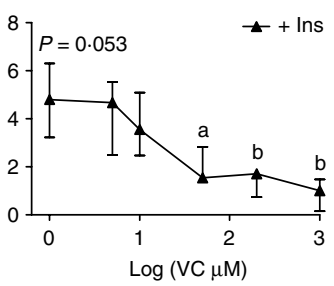

Kruskal-Wallis $P<0.01$

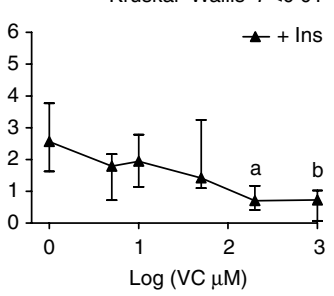

Kruskal-Wallis $P<0.001$

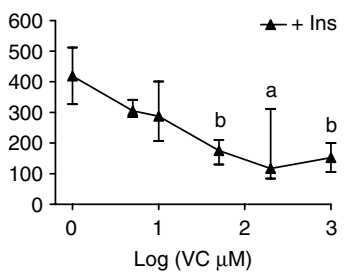

Figure 1 Effects of vitamin $\mathrm{C}(\log (5-1000 \mu \mathrm{M}))$ in the absence (white circles) or presence (black triangles) of $1.6 \mathrm{nM}$ insulin on (A) glucose uptake, (B) lactate production, and (C) glycerol release in isolated rat adipocytes over $72 \mathrm{~h}$ in culture. Data $(n \geq 4$, median and interquartile range). ${ }^{\mathrm{a}} P<0.05$ and ${ }^{\mathrm{b}} P<0.01$ versus control cells (with or without insulin treatment). $P=0.053$, control versus control+insulin cells. VC, vitamin C; Ins, insulin.

$200 \mu \mathrm{M}$ VC for both untreated $(P<0.05$ for 200 and $1000 \mu \mathrm{M}$ versus control cells) and insulin-treated cells $(P<0.05$ for 200 and $P<0.01$ for $1000 \mu \mathrm{M}$ versus cells treated with insulin alone). The percentage of glucose converted to lactate was not affected by either VC or insulin treatment (data not shown).

Finally, the amount of glycerol released (Fig. 1C), as a lipolysis marker, showed a VC-reduced pattern that was nearly the same as that shown by lactate that was produced, presenting significant differences in noninsulin-treated cells at VC concentrations of 200 and $1000 \mu \mathrm{M}(P<0 \cdot 01$ for both versus control cells $)$ and in insulin-treated cells at $50(P<0 \cdot 01), 200(P<0 \cdot 05)$, and $1000 \mu \mathrm{M}(P<0 \cdot 01)$ compared with the cells treated with insulin alone.

\section{Adipokine secretion}

The role of $\mathrm{VC}$ in the secretion of different adipokines by the adipocytes was also evaluated (Fig. 2). In first instance, leptin secretion into the culture medium after $72 \mathrm{~h}$ was detected (Fig. 2A), and significant effects of

insulin and $\mathrm{VC}$ treatment on its secretion were observed $(P<0 \cdot 001)$. Increasing concentrations of VC induced a dose-dependent inhibition on both basal $(P<0 \cdot 05$ for 200 and $1000 \mu \mathrm{M}$ versus control cells) and insulinstimulated leptin secretion $(P<0.01$ for 200 and $1000 \mu \mathrm{M}$ versus insulin-treated cells). Insulin treatment effectively induced leptin secretion with respect to the control cells $(P<0 \cdot 05)$. In contrast, in the case of adiponectin, despite the fact that a significant global effect was detected $(P<0 \cdot 05)$, no differences among experimental groups were observed (Fig. 2B). Finally, concerning visfatin secretion into the culture medium, no significant differences were detected in the VC-treated cells (Fig. 2C).

Furthermore, the leptin secretion into the culture medium presented positive and significant correlations with the glucose uptake of the VC-treated adipocytes in both untreated $(r=0.566, P<0.01)$ and insulinstimulated cells $(r=0.797, P<0 \cdot 001$; Fig. $3 \mathrm{~A}$ and $\mathrm{B}$ respectively), and also with glycerol release in both untreated $(r=0 \cdot 787, P<0 \cdot 001)$ and insulin-stimulated cells $(r=0 \cdot 791, P<0 \cdot 001$; Fig. $3 \mathrm{C}$ and $\mathrm{D}$ respectively).
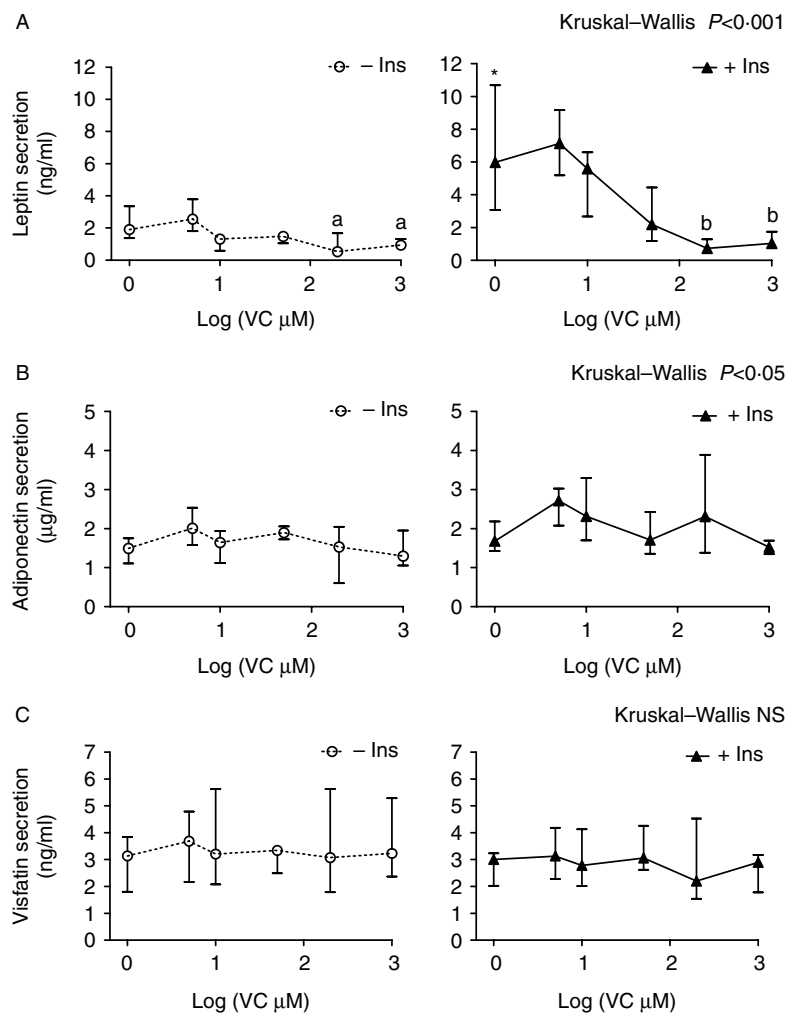

Figure 2 Effects of vitamin $\mathrm{C}(\log (5-1000 \mu \mathrm{M}))$ in the absence (white circles) or presence (black triangles) of $1.6 \mathrm{nM}$ insulin on (A) leptin, (B) adiponectin, and (C) visfatin secretion in isolated rat adipocytes over $72 \mathrm{~h}$ in culture. Data $(n \geq 4$, median and interquartile range). ${ }^{\mathrm{a}} P<0.05$ and ${ }^{\mathrm{b}} P<0.01$ versus control cells (with or without insulin treatment). ${ }^{\star} P<0.05$, control versus control+insulin cells. VC, vitamin C; Ins, insulin; NS, not significant. 

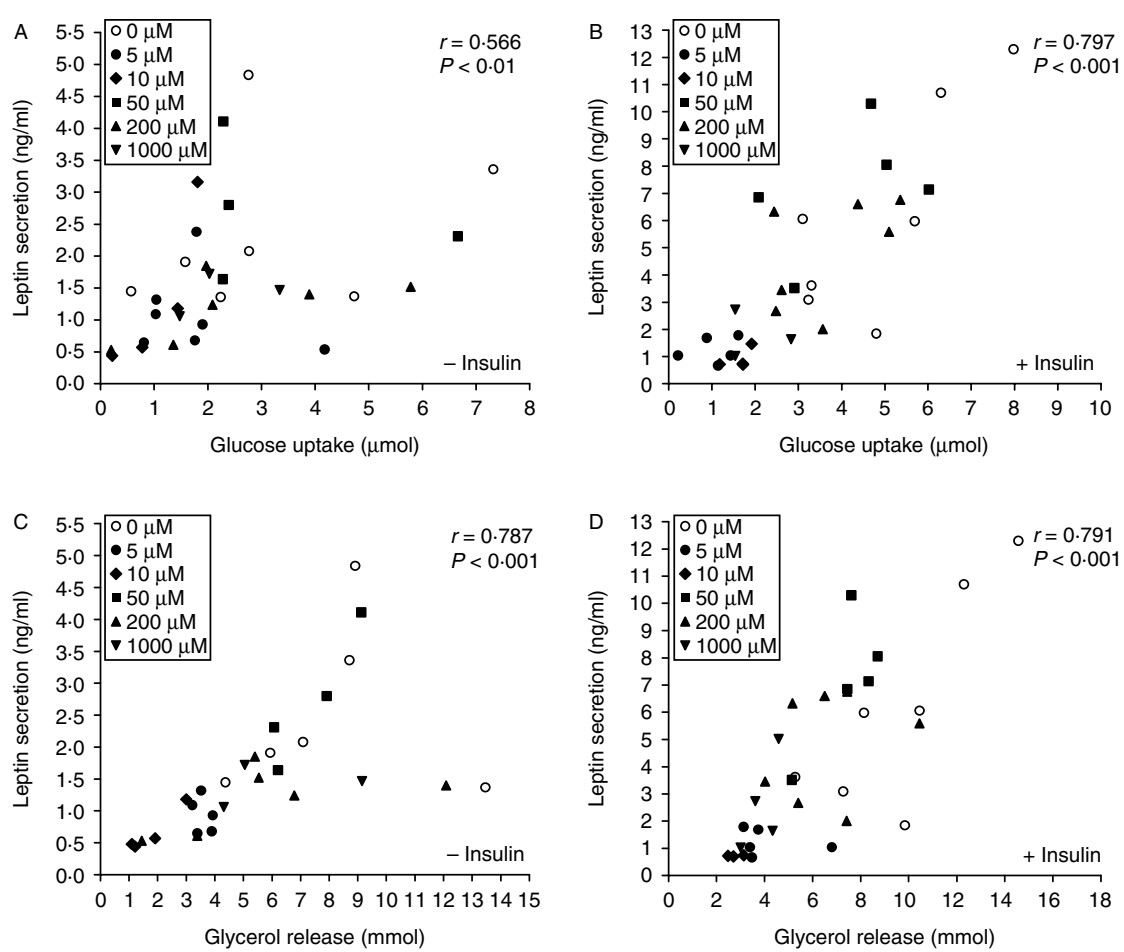

Figure 3 Analysis of the association between leptin secretion and (A) basal glucose uptake, (B) insulin-stimulated glucose uptake, and the amount of glycerol released in the (C) absence and (D) presence of insulin. All the VC concentrations $(0-1000 \mu \mathrm{M})$ are included. Graph symbols represent: open circles, $0 \mu \mathrm{M}$; closed circles, $5 \mu \mathrm{M}$; diamonds, $10 \mu \mathrm{M}$; squares, $50 \mu \mathrm{M}$; triangles, $200 \mu \mathrm{M}$; and inverted triangles, $1000 \mu \mathrm{M}$ VC concentrations. $r$, Spearman's correlation coefficient.

\section{mRNA expression of specific adipokines and obesity-related genes}

For these analyses, $200 \mu \mathrm{M}$ VC and control samples were chosen for total mRNA extraction followed by gene expression of the three selected adipokines. This concentration was considered physiological according to Levine et al. (1996). Leptin mRNA expression presented no significant differences in insulin- or VC-treated cells (Fig. 4A), but a correlation with the glucose uptake in insulin-stimulated cells $(r=0 \cdot 810$, $P<0.05)$ was detected. Regarding the other assayed adipokines, no statistically significant differences were observed in adiponectin mRNA expression (Fig. 4B), but a slightly significant effect of the treatments on visfatin gene expression was detected (Fig. 4C), probably induced by the elevated mRNA expression found in VC+insulin-treated adipocytes.

Gene expression of several other genes involved in obesity-related mechanism was also examined. Important and significant modifications were observed in the Gpdh mRNA expression $(P<0 \cdot 05)$, induced mainly by a drastic inhibition observed in the $\mathrm{VC}+$ insulin-treated adipocytes (Fig. 5A). The Irs3 gene expression (Fig. 5B) was not significantly modified by insulin or VC treatment. Finally, the Cdkn1a and Casp8 mRNA expressions presented significant modifications $(P<0.05$ for both), mainly due to the observed inducing effects of the $\mathrm{VC}$ treatment (Fig. 5D and E).

\section{ROS production}

Intracellular and extracellular ROS concentrations were measured after the 72-h treatment. Marked effects $(P<0.05)$ were detected on the intracellular ROS concentration of the isolated adipocytes, mainly due to the inhibition observed in insulin-treated cells (Fig. 6A). On the other hand, the extracellular ROS levels also presented reductions $(P<0.05)$ induced by VC incubation in both insulin-untreated and insulintreated cells (Fig. 6B).

\section{Discussion}

Available data show inconclusive evidences regarding possible relationships between antioxidant treatments and obesity prevention or treatment mechanisms (Valdecantos et al. 2009). Research with antioxidants, 

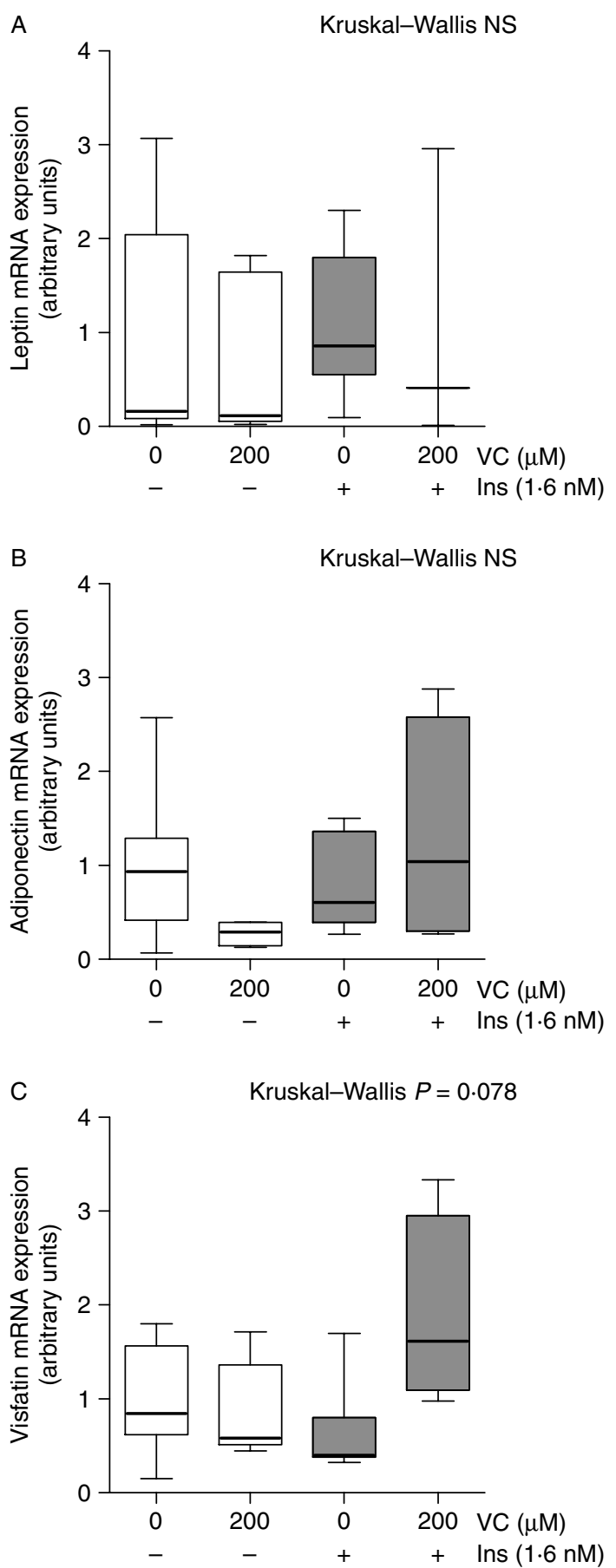

Figure 4 Effects of vitamin $\mathrm{C}(200 \mu \mathrm{M})$ in the absence (white boxes) or presence (grey boxes) of $1.6 \mathrm{nM}$ insulin on (A) leptin, (B) adiponectin, and (C) visfatin mRNA expressions in isolated rat adipocytes over $72 \mathrm{~h}$ in culture. Data $(n \geq 4$, median and interquartile range). VC, vitamin C; Ins, insulin; NS, not significant.

which are labile products, could have discrepant outcomes concerning metabolic changes due to experimental conditions. However, in humans, inverse associations between VC plasma levels and body mass index (Johnston 2005), waist-hip ratio (Canoy et al. 2005), and cardiovascular disease risk were observed (Kurl et al. 2002). Moreover, a VC supplementation induced some beneficial effects on glucose and lipid metabolism in type 2 diabetic patients (Paolisso et al. 1995).

In animal studies, it was observed that VC supplementation induced insulin resistance improvement in hyperglycemic $o b / o b$ mice (Abdel-Wahab et al. 2002), and decreased body weight gain in guinea pigs (Sorensen et al. 1974). Studies by our research group have found a high-fat diet-induced adiposity reduction by VC supplementation in rats (Campion et al. 2006, Garcia-Diaz et al. 2007) and modifications in adipocyte catecholamine-induced lipolysis (Garcia-Diaz et al. 2009). In vitro studies have reported controversial VC effects on adipocyte differentiation (Ono et al. 1990, Krieger-Brauer \& Kather 1995, Galinier et al. 2006).

In the present study, in vitro effects of VC incubation on epididymal rat adipocyte metabolism and secretory functions were evaluated. The glucose uptake inhibition observed in adipocytes without insulin treatment, and especially in adipocytes under insulin treatment, could be partially explained by the fact that dehydroascorbic acid (DHA; the oxidized form of VC that is transported inside cells) possibly competes with glucose for GLUT1 (SLC2A1) and GLUT3 (SLC2A3; Arrigoni \& De Tullio 2002), and for GLUT4 (SLC2A4; Vera et al. 1993) transporters respectively. However, it was reported previously that in primary cultures of rat hippocampal neurons, VC accumulation inhibited the glucose transport inside the cytoplasm independently of this competition (Patel et al. 2001). The lactate production inhibition by $\mathrm{VC}$ is in agreement with a study that described a lactic acid plasma concentration decrease in rats with streptozotocin-induced diabetes by a VC/E treatment (Ruperez et al. 2008). On the other hand, no statistical effects of VC were observed on the percentage of glucose carbon released as lactate, suggesting that VC did not participate in the aerobic/ anaerobic metabolism of rat adipocytes over a 72-h culture treatment. Finally, the results showed no glycerol modulation release by insulin. Although the antilipolytic properties of this molecule are well known (Elks \& Manganiello 1985), the present data are in agreement with the data reported by Perez-Matute $e t a l$. (2007), indicating the lack of lipolysis modulation by insulin in this experimental model. Despite this, the lower glycerol release induced by VC may indicate inhibited fat utilization in both insulin-treated and non-treated adipocytes. It has been described that rats fed with high-fat diet with VC supplementation presented a decreased isoproterenol-induced lipolysis compared with the rats fed with high-fat diet alone (Garcia-Diaz et al. 2009). 

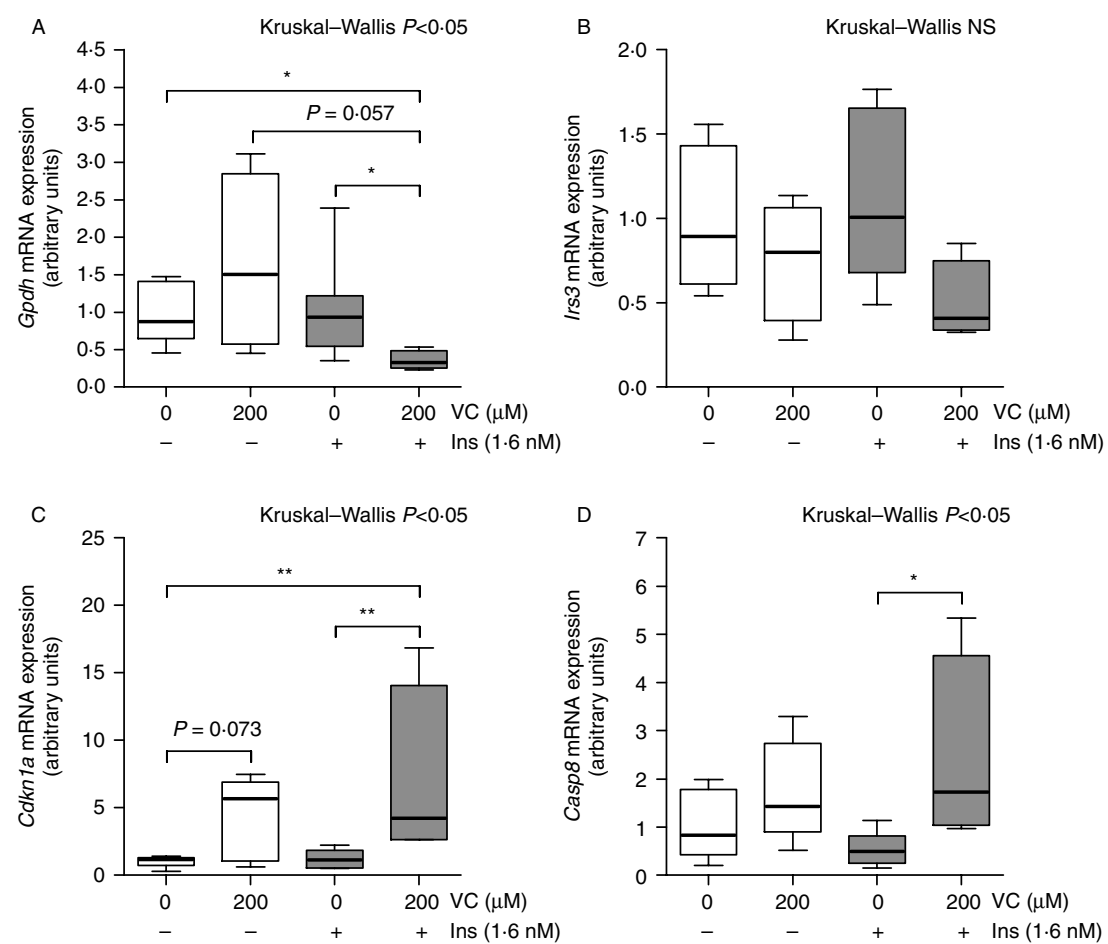

Figure 5 Effects of vitamin $\mathrm{C}(200 \mu \mathrm{M})$ in the absence (white boxes) or presence (grey boxes) of $1.6 \mathrm{nM}$ insulin on mRNA expression of several genes involved in $(A)$ adipocyte differentiation (Gpdh), (B) insulin signaling (Irs3), (C) cell cycle (Cdkn1a), and (D) apoptosis (Casp8) in isolated rat adipocytes over $72 \mathrm{~h}$ in culture. Data $(n \geq 4$, median and interquartile range). VC, vitamin $\mathrm{C}$; Ins, insulin; ${ }^{\star} P<0.05$; ${ }^{\star \star} P<0.01$; NS, not significant.

Regarding the secretion and expression of some adipokines, this study has demonstrated an important inhibitory effect of VC on leptin secretion, which is in agreement with the previously reported reducing effects on leptin circulatory levels of a diet with VC supplementation given to high-fat diet-fed rats for 56 days (Garcia-Diaz et al. 2007). In that work, the observed reduction in leptin secretion was accompanied by a decrease in body weight and adiposity. However, the results of the present study suggest that the leptin secretion inhibition was mainly due to specific effects of the VC treatment over the adipocytes and not due to mass-reducing effects on the leptin secretor tissue. In another study, it was reported that the leptin expression and secretion in cultured rat adipocytes were decreased by glucose uptake inhibition (Mueller et al. 1998). In the present study, the positive correlation between leptin secretion and glucose uptake observed in both insulin-treated and nontreated cells suggests at first glance that the glucose uptake inhibition by VC itself could be determining the leptin secretion. In this context, previous studies indicated that glucose utilization stimulates leptin production by driving the glucose metabolism to oxidation or lipogenesis, rather than anaerobic lactate production (Mueller et al. 2000). Moreover, leptin secretion presented significant positive associations with glycerol release. This could be explained by reports describing that leptin directly inhibits lipogenesis (Ramsay 2003) and stimulates lipolysis in adipocytes (Fruhbeck et al. 1997). This feature could also in part explain the lower glycerol release occurring in the VC-incubated adipocytes. The fact that insulin induced no higher leptin gene expression could be explained by possible mRNA expression fluctuations during culture. Therefore, the elevated leptin secretion observed in insulin-treated cells could be due to an induced gene expression that decreased time-dependently, which was undetected at the end of the treatment. It was described that insulin-treated primary culture epididymal adipocytes produced more leptin during the first $2 \mathrm{~h}$ of in vitro incubations (Barr et al. 1997). Also, an acute significant increase in leptin secretion after a 2-h $100 \mathrm{nM}$ insulin treatment, without changes in its gene expression (Bradley \& Cheatham 1999), was observed. Moreover, it was described that biosynthetic release rates of leptin correlate with tissue leptin content and adiposity, but not with leptin mRNA levels in humans (Lee et al. 2007a). Finally, the lack of effects observed on the leptin mRNA expression by VC could be due to the well-known ascorbic acid instability (Feng et al. 1977), and also could be due to the lack of insulin effects, since 

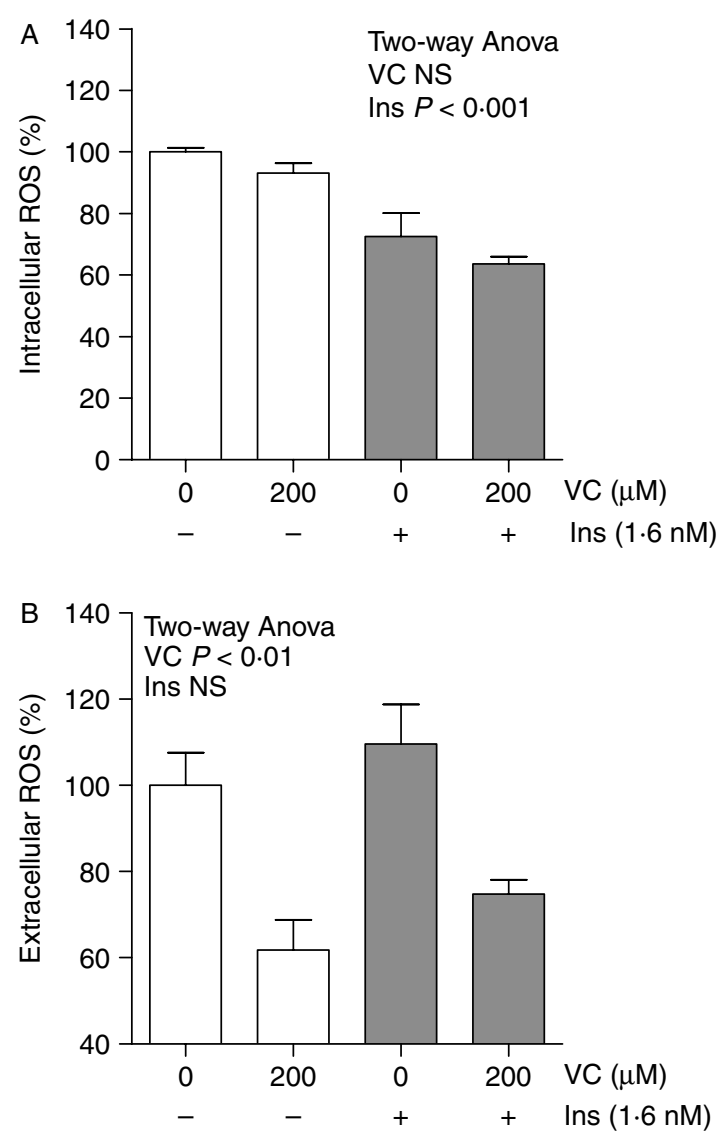

Figure 6 Effects of vitamin $C(200 \mu \mathrm{M})$ in the absence or presence of $1.6 \mathrm{nM}$ insulin on intracellular (A) and extracellular (B) ROS formation in isolated rat adipocytes over $72 \mathrm{~h}$ in culture. Data are expressed in percentage ( $n=3$, mean \pm S.E.M). VC, vitamin C; Ins, insulin.

the most dramatic inhibitory effects of VC were observed on insulin-induced leptin secretion. Furthermore, no data evidencing a possible intracellular leptin accumulation by VC have been reported previously. In any case, mRNA levels do not always correlate with the given protein product, perhaps by post-transcriptional regulation mechanisms (Lackner \& Bahler 2008). In fact, it is known that both feeding and insulin treatments increase leptin translation (Lee et al. 2007b).

Regarding the mRNA expression analysis of other obesity-related genes, the data suggest that VC treatment could possibly modify some mechanisms related to adipocyte differentiation, insulin resistance, inflammation, and apoptosis. In the present study, a lowering effect of VC+insulin co-treatment on Gpdh mRNA expression was observed. The available literature reported a reduced GPDH activity in mature adipocytes exposed to VC treatment (Hasegawa et al. 2002) and differentiation inhibition, and consequently, reduced GPDH activity in 3T3-L1 cells (Krieger-Brauer \& Kather 1995). On the other hand, it is known that insulin is necessary for triglyceride accumulation in preadipocytes (Ntambi \& Young-Cheul 2000). In fact, the utilization of insulin for differentiation induction of different preadipocytes cell lines is common (Ailhaud 1997). However, the treated adipocytes in this study were mature cells isolated directly from WAT that did not present important differentiation machinery activity. This contradicts the lipolytic properties described for VC (Hasegawa et al. 2002), but this could be explained by an extra down-regulation of the lipogenic pathways by VC treatment.

It has been observed that VC induced a slight decrease in Irs 3 mRNA expression in subcutaneous and retroperitoneal fat pads of high-fat VC-supplemented diet-fed rats with respect to the high-fat diet-alone-fed obese rats (Garcia-Diaz et al. 2007). This slight mRNA inhibition was also observed in the current study, especially in cells under insulin treatment, suggesting a direct relationship between $\mathrm{VC}$ and insulin resistance/sensitivity pathways. It has been described earlier that Irs 3 overexpression induces higher translocation of GLUT4 proteins to the membranes of rat adipose cells, and also that mutant and non-functional IRS3 inhibits insulin action (Zhou et al. 1999). Consequently, down-regulation of this gene could have contributed to the observed glucose uptake VC-mediated inhibition. However, some insulin sensitivity improvement effects of a VC supplementation in high-fat diet-fed rats have been described previously (Garcia-Diaz et al. 2009). Therefore, these systemic insulin-sensitizing effects of VC could be driven through other mechanisms rather than through IRS3 modulation in adipocytes.

The Cdkn1a and Casp 8 mRNA overexpression observed in VC-treated adipocytes could indicate an induced cell apoptosis (Hershenson 2004, Baumgartner et al. 2007). These results are in agreement with the data reported by Senen $e t$ al. (2002), who described how VC injections in WAT deposits of rats decrease adipocyte cell number. Despite this evidence, no effect of $200 \mu \mathrm{M}$ VC treatment on cell integrity/viability has been observed, suggesting that the expression of these genes was not directly related to cell death. Furthermore, in a study by our research group (Boque et al. 2009), a reduced mRNA expression of Cdkn1a and $p 57$ in subcutaneous WAT of rats fed with a high-fat diet with respect to the controls was observed, suggesting that this process could lead to higher adipose cell proliferation. It was also observed that a VC dietary supplementation induced slightly, but not significantly, the $C d k n 1 a$ and $p 57$ gene expressions with respect to a high-fat-alone-fed group, which is in agreement with the data reported in the present work.

It has been described that oxidative stress in excessively accumulated adipose tissue is an important trigger for the onset of obesity-related metabolic syndrome features (Furukawa et al. 2004). Some studies 
described an important ROS-scavenging effect of this antioxidant vitamin (Perticone et al. 2001, Arrigoni \& De Tullio 2002). Besides, it has been observed that an induced oxidative stress decreased GLUT4 expression by impairing the protein binding to its promoter, reducing glucose uptake (Pessler et al. 2001). On the other hand, another study described that a ROS production pathway stimulation is related to higher GLUT1 transcription (Kao \& Fong 2008). It is known that the oxidized form of VC (DHA) is preferentially transported by GLUT1 (Vera et al. 1993), suggesting that VC could also induce the glucose uptake inhibition observed due to its ROS-scavenging properties. Therefore, the present results suggest that VC treatment could be involved in ROS formation, indicating that this inhibition could be implicated in some of the metabolic effects described earlier.

Taking all these into account, even though leptin is a recognized insulin-sensitizing agent (Dyck 2009), the inhibited secretion of this adipokine induced by $\mathrm{VC}$ counteracts the possible insulin improvement properties of this molecule. However, other previously observed effects of this vitamin, such as inhibition of the lipolytic rate (Garcia-Diaz et al. 2009) and oxidative stress inhibition (Vincent et al. 2009), could be associated with this possible beneficial effect, both of which are in agreement with the present results.

In summary, VC inhibited some glucose and lipid metabolism indicators, and also reduced the secretion of leptin and modified the expression of some important obesity-related proteins in primary culture rat adipocytes. The glucose uptake decrease could be due to VC-glucose transport competition, a fact that possibly leads to leptin secretion inhibition, which in turn could drive the observed lipolysis inhibition. Also, the effects of VC on ROS modulations could be involved in glucose and lipid metabolism regulation. The possible insulin-sensitizing properties of $\mathrm{VC}$ could also be attributed to other systemic effects rather than to direct inhibitory effects on leptin secretion in isolated adipocytes.

\section{Declaration of interest}

The authors declare that there is no conflict of interest that could be perceived as prejudicing the impartiality of the research reported.

\section{Funding}

This work was supported by the Ministry for Education and Science (MEC, Spain; grant AGL2006-04716/ALI), the Education Department of the Navarra Government (Spain), and the Carlos III Health Institute (CIBER project, Spain; grant CB06/03/1017), as well as by the 'Línea Especial' (LE/97) from the University of Navarra (Spain). D F Garcia-Diaz was supported by a doctoral grant of the 'Asociación de Amigos de la Universidad de Navarra' and IBERCAJA (Spain).

\section{Acknowledgements}

The authors wish to thank the Department of Biochemistry of the University of Navarra for lending the POLARstar spectrofluorometer plate reader for ROS concentration measurements. The authors are also grateful for the expert technical assistance of Ana Lorente and Veronica Ciaurriz.

\section{References}

Abdel-Wahab YH, O'Harte FP, Mooney MH, Barnett CR \& Flatt PR 2002 Vitamin C supplementation decreases insulin glycation and improves glucose homeostasis in obese hyperglycemic $(\mathrm{ob} / \mathrm{ob})$ mice. Metabolism: Clinical and Experimental 51 514-517.

Ailhaud G 1997 Molecular mechanisms of adipocyte differentiation. Journal of Endocrinology 155 201-202.

Arrigoni O \& De Tullio MC 2002 Ascorbic acid: much more than just an antioxidant. Biochimica et Biophysica Acta 1569 1-9.

Barr VA, Malide D, Zarnowski MJ, Taylor SI \& Cushman SW 1997 Insulin stimulates both leptin secretion and production by rat white adipose tissue. Endocrinology 138 4463-4472.

Baumgartner HK, Gerasimenko JV, Thorne C, Ashurst LH, Barrow SL, Chvanov MA, Gillies S, Criddle DN, Tepikin AV, Petersen OH et al. 2007 Caspase-8-mediated apoptosis induced by oxidative stress is independent of the intrinsic pathway and dependent on cathepsins. American Journal of Physiology. Gastrointestinal and Liver Physiology 293 G296-G307.

Boque N, Campion J, Milagro FI, Moreno-Aliaga MJ \& Martinez JA 2009 Some cyclin-dependent kinase inhibitors-related genes are regulated by vitamin $\mathrm{C}$ in a model of diet-induced obesity. Biological and Pharmaceutical Bulletin 32 1462-1468.

Bradley RL \& Cheatham B 1999 Regulation of ob gene expression and leptin secretion by insulin and dexamethasone in rat adipocytes. Diabetes 48 272-278.

Brandt R \& Keston AS 1965 Synthesis of diacetyldichlorofluorescin: a stable reagent for fluorometric analysis. Analytical Biochemistry 11 $6-9$

Bray GA 2004 Medical consequences of obesity. Journal of Clinical Endocrinology and Metabolism 89 2583-2589.

Bsoul SA \& Terezhalmy GT 2004 Vitamin C in health and disease. Journal of Contemporary Dental Practice 5 1-13.

Cai D, Yuan M, Frantz DF, Melendez PA, Hansen L, Lee J \& Shoelson SE 2005 Local and systemic insulin resistance resulting from hepatic activation of IKK-beta and NF-kappaB. Nature Medicine 11 183-190.

Campion J \& Martinez J 2004 Ketoconazole, an antifungal agent, protects against adiposity induced by a cafeteria diet. Hormone and Metabolic Research 36 485-491.

Campion J, Milagro FI, Fernandez D \& Martinez JA 2006 Diferential gene expression and adiposity reduction induced by ascorbic acid supplementation in a cafeteria model of obesity. Journal of Physiology and Biochemistry 62 71-80.

Canoy D, Wareham N, Welch A, Bingham S, Luben R, Day N \& Khaw KT 2005 Plasma ascorbic acid concentrations and fat distribution in 19,068 British men and women in the European Prospective Investigation into Cancer and Nutrition Norfolk cohort study. American Journal of Clinical Nutrition $\mathbf{8 2}$ 1203-1209.

Carcamo JM, Pedraza A, Borquez-Ojeda O \& Golde DW 2002 Vitamin C suppresses TNF alpha-induced NF kappa B activation by inhibiting I kappa B alpha phosphorylation. Biochemistry 41 12995-13002.

Doulas NL, Constantopoulos A \& Litsios B 1987 Effect of ascorbic acid on guinea pig adrenal adenylate cyclase activity and plasma cortisol. Journal of Nutrition 117 1108-1114. 
Dyck DJ 2009 Adipokines as regulators of muscle metabolism and insulin sensitivity. Applied Physiology, Nutrition, and Metabolism 34 396-402.

Elks ML \& Manganiello VC 1985 Antilipolytic action of insulin: role of cAMP phosphodiesterase activation. Endocrinology 116 2119-2121.

Fantuzzi G 2005 Adipose tissue, adipokines, and inflammation. Journal of Allergy and Clinical Immunology 115 911-919.

Feng J, Melcher AH, Brunette DM \& Moe HK 1977 Determination of L-ascorbic acid levels in culture medium: concentrations in commercial media and maintenance of levels under conditions of organ culture. In Vitro 13 91-99.

Ferrante AW 2007 Obesity-induced inflammation: a metabolic dialogue in the language of inflammation. Journal of Internal Medicine 262 408-414.

Flora SJ 2007 Role of free radicals and antioxidants in health and disease. Cellular and Molecular Biology 53 1-2.

Fruhbeck G, Aguado M \& Martinez JA 1997 In vitro lipolytic effect of leptin on mouse adipocytes: evidence for a possible autocrine/ paracrine role of leptin. Biochemical and Biophysical Research Communications 240 590-594.

Fu J, Liang X, Chen Y, Tang L, Zhang QH \& Dong Q 2008 Oxidative stress as a component of chromium-induced cytotoxicity in rat calvarial osteoblasts. Cell Biology and Toxicology 24 201-212.

Fukuhara A, Matsuda M, Nishizawa M, Segawa K, Tanaka M, Kishimoto K, Matsuki Y, Murakami M, Ichisaka T, Murakami H et al. 2005 Visfatin: a protein secreted by visceral fat that mimics the effects of insulin. Science 307 426-430.

Furukawa S, Fujita T, Shimabukuro M, Iwaki M, Yamada Y, Nakajima Y, Nakayama O, Makishima M, Matsuda M \& Shimomura I 2004 Increased oxidative stress in obesity and its impact on metabolic syndrome. Journal of Clinical Investigation 114 1752-1761.

Galinier A, Carriere A, Fernandez Y, Carpene C, Andre M, Caspar-Bauguil S, Thouvenot JP, Periquet B, Penicaud L \& Casteilla L 2006 Adipose tissue proadipogenic redox changes in obesity. Journal of Biological Chemistry 281 12682-12687.

Garcia-Diaz D, Campion J, Milagro FI \& Martinez JA 2007 Adiposity dependent apelin gene expression: relationships with oxidative and inflammation markers. Molecular and Cellular Biochemistry 305 87-94.

Garcia-Diaz DF, Campion J, Milagro FI, Paternain L, Solomon A \& Martinez JA 2009 Ascorbic acid oral treatment modifies lipolytic response and behavioural activity but not glucocorticoid metabolism in cafeteria diet fed rats. Acta Physiologica 195 449-457.

Haider DG, Schindler K, Schaller G, Prager G, Wolzt M \& Ludvik B 2006 Increased plasma visfatin concentrations in morbidly obese subjects are reduced after gastric banding. Journal of Clinical Endocrinology and Metabolism 91 1578-1581.

Hasegawa N, Niimi N \& Odani F 2002 Vitamin C is one of the lipolytic substances in green tea. Phytotherapy Research 16 91-92.

Hershenson MB 2004 p21Wafl/Cip1 and the prevention of oxidative stress. American Journal of Physiology. Lung Cellular and Molecular Physiology 286 L502-L505.

Johnston CS 2005 Strategies for healthy weight loss: from vitamin C to the glycemic response. Journal of the American College of Nutrition $\mathbf{2 4}$ 158-165.

Kao YS \& Fong JC 2008 Endothelin-1 induces glut1 transcription through enhanced interaction between Sp1 and NF-kappaB transcription factors. Cellular Signalling 20 771-778.

Kim JY, van de Wall E, Laplante M, Azzara A, Trujillo ME, Hofmann SM, Schraw T, Durand JL, Li H, Li G et al. 2007 Obesity-associated improvements in metabolic profile through expansion of adipose tissue. Journal of Clinical Investigation 117 2621-2637.

Krieger-Brauer HI \& Kather H 1995 Antagonistic effects of different members of the fibroblast and platelet-derived growth factor families on adipose conversion and NADPH-dependent $\mathrm{H}_{2} \mathrm{O}_{2}$ generation in 3T3 L1-cells. Biochemical Journal 307 549-556.

Kurl S, Tuomainen TP, Laukkanen JA, Nyyssonen K, Lakka T, Sivenius J \& Salonen JT 2002 Plasma vitamin C modifies the association between hypertension and risk of stroke. Stroke 33 1568-1573.
Lackner DH \& Bahler J 2008 Translational control of gene expression from transcripts to transcriptomes. International Review of Cell and Molecular Biology 271 199-251.

Lee MJ, Wang Y, Ricci MR, Sullivan S, Russell CD \& Fried SK $2007 a$ Acute and chronic regulation of leptin synthesis, storage, and secretion by insulin and dexamethasone in human adipose tissue. American Journal of Physiology. Endocrinology and Metabolism 292 E858-E864.

Lee MJ, Yang RZ, Gong DW \& Fried SK $2007 b$ Feeding and insulin increase leptin translation. Importance of the leptin mRNA untranslated regions. Journal of Biological Chemistry 282 72-80.

Levine M, Conry-Cantilena C, Wang Y, Welch RW, Washko PW, Dhariwal KR, Park JB, Lazarev A, Graumlich JF, King J et al. 1996 Vitamin C pharmacokinetics in healthy volunteers: evidence for a recommended dietary allowance. PNAS 93 3704-3709.

Lorente-Cebrian S, Bustos M, Marti A, Martinez JA \& Moreno-Aliaga MJ 2009 Eicosapentaenoic acid stimulates AMP-activated protein kinase and increases visfatin secretion in cultured murine adipocytes. Clinical Science 117 243-249.

Martinez JA 2006 Mitochondrial oxidative stress and inflammation: an slalom to obesity and insulin resistance. Journal of Physiology and Biochemistry 62 303-306.

Milagro FI, Campion J \& Martinez JA 2006 Weight gain induced by high-fat feeding involves increased liver oxidative stress. Obesity 14 1118-1123.

Misekova D, Lincova D \& Hynie S 1993 The effect of ascorbic acid on adrenergic lipolysis. Sborník Lékarský 94 55-62.

Moreno-Aliaga M, Campion J, Milagro FI, Berjon A \& Martinez JA 2005 Adiposity and proinflammatory state: the chicken or the egg. Adipocytes 1 1-16.

Mueller WM, Gregoire FM, Stanhope KL, Mobbs CV, Mizuno TM, Warden CH, Stern JS \& Havel PJ 1998 Evidence that glucose metabolism regulates leptin secretion from cultured rat adipocytes. Endocrinology 139 551-558.

Mueller WM, Stanhope KL, Gregoire F, Evans JL \& Havel PJ 2000 Effects of metformin and vanadium on leptin secretion from cultured rat adipocytes. Obesity Research 8 530-539.

Mutlu-Turkoglu U, Oztezcan S, Telci A, Orhan Y, Aykac-Toker G, Sivas A \& Uysal M 2003 An increase in lipoprotein oxidation and endogenous lipid peroxides in serum of obese women. Clinical and Experimental Medicine 2 171-174.

Ntambi JM \& Young-Cheul K 2000 Adipocyte differentiation and gene expression. Journal of Nutrition 130 3122S-3126S.

Ono M, Aratani Y, Kitagawa I \& Kitagawa Y 1990 Ascorbic acid phosphate stimulates type IV collagen synthesis and accelerates adipose conversion of 3T3-L1 cells. Experimental Cell Research 187 309-314.

Paolisso G, Balbi V, Volpe C, Varricchio G, Gambardella A, Saccomanno F, Ammendola S, Varricchio M \& D'Onofrio F 1995 Metabolic benefits deriving from chronic vitamin C supplementation in aged non-insulin dependent diabetics. Journal of the American College of Nutrition 14 387-392.

Patel M, McIntosh L, Bliss T, Ho D \& Sapolsky R 2001 Interactions among ascorbate, dehydroascorbate and glucose transport in cultured hippocampal neurons and glia. Brain Research 916 $127-135$.

Perez-Matute P, Marti A, Martinez JA, Fernandez-Otero MP, Stanhope KL, Havel PJ \& Moreno-Aliaga MJ 2007 Conjugated linoleic acid inhibits glucose metabolism, leptin and adiponectin secretion in primary cultured rat adipocytes. Molecular and Cellular Endocrinology $26850-58$.

Perticone F, Ceravolo R, Candigliota M, Ventura G, Iacopino S, Sinopoli F \& Mattioli PL 2001 Obesity and body fat distribution induce endothelial dysfunction by oxidative stress: protective effect of vitamin C. Diabetes 50 159-165.

Pessler D, Rudich A \& Bashan N 2001 Oxidative stress impairs nuclear proteins binding to the insulin responsive element in the GLUT4 promoter. Diabetologia 44 2156-2164. 
Powers KA, Rehrig ST \& Jones DB 2007 Financial impact of obesity and bariatric surgery. Medical Clinics of North America 91 321-338.

Ramsay TG 2003 Porcine leptin inhibits lipogenesis in porcine adipocytes. Journal of Animal Science 81 3008-3017.

Ruperez FJ, Garcia-Martinez D, Baena B, Maeso N, Cifuentes A, Barbas C \& Herrera E 2008 Evolution of oxidative stress parameters and response to oral vitamins $\mathrm{E}$ and $\mathrm{C}$ in streptozotocininduced diabetic rats. Journal of Pharmacy and Pharmacology 60 871-878.

Senen D, Adanali G, Ayhan M, Gorgu M \& Erdogan B 2002 Contribution of vitamin $\mathrm{C}$ administration for increasing lipolysis. Aesthetic Plastic Surgery 26 123-125.

Sorensen DI, Devine MM \& Rivers JM 1974 Catabolism and tissue levels of ascorbic acid following long-term massive doses in the guinea pig. Journal of Nutrition 104 1041-1048.

Valdecantos MP, Perez-Matute P \& Martinez JA 2009 Obesity and oxidative stress: role of antioxidant supplementation. Revista de Investigación Clínica 61 127-139.

Vandesompele J, De Preter K, Pattyn F, Poppe B, Van Roy N, De Paepe A \& Speleman F 2002 Accurate normalization of real-time quantitative RT-PCR data by geometric averaging of multiple internal control genes. Genome Biology 3 research0034.1research0034.11.

Varma V, Yao-Borengasser A, Rasouli N, Bodles AM, Phanavanh B, Lee MJ, Starks T, Kern LM, Spencer HJ, McGehee RE et al. 2007 Human visfatin expression: relationship to insulin sensitivity, intramyocellular lipids, and inflammation. Journal of Clinical Endocrinology and Metabolism 92 666-672.
Vera JC, Rivas CI, Fischbarg J \& Golde DW 1993 Mammalian facilitative hexose transporters mediate the transport of dehydroascorbic acid. Nature 364 79-82.

Vincent HK \& Taylor AG 2006 Biomarkers and potential mechanisms of obesity-induced oxidant stress in humans. International Journal of Obesity 30 400-418.

Vincent HK, Bourguignon CM, Weltman AL, Vincent KR, Barrett E, Innes KE \& Taylor AG 2009 Effects of antioxidant supplementation on insulin sensitivity, endothelial adhesion molecules, and oxidative stress in normal-weight and overweight young adults. Metabolism: Clinical and Experimental 58 254-262.

Yuan M, Konstantopoulos N, Lee J, Hansen L, Li ZW, Karin M \& Shoelson SE 2001 Reversal of obesity- and diet-induced insulin resistance with salicylates or targeted disruption of Ikkbeta. Science 293 1673-1677.

Zhang Y, Proenca R, Maffei M, Barone M, Leopold L \& Friedman JM 1994 Positional cloning of the mouse obese gene and its human homologue. Nature 372 425-432.

Zhou L, Chen H, Xu P, Cong LN, Sciacchitano S, Li Y, Graham D, Jacobs AR, Taylor SI \& Quon MJ 1999 Action of insulin receptor substrate-3 (IRS-3) and IRS-4 to stimulate translocation of GLUT4 in rat adipose cells. Molecular Endocrinology 13 505-514.

Received in final form 22 March 2010

Accepted 16 April 2010

Made available online as an Accepted Preprint

16 April 2010 